\title{
Outcome of Non-Descent Vaginal Hysterectomy at a Single Centre in Sri Lanka: an Observational Study
}

\author{
Hiran Chaminda $\mathrm{SH}^{1}$, Ekanayake $\mathrm{CD}^{2}$, Sriskanthan $\mathrm{RS}^{1}$, Perera $\mathrm{B}^{3}$, Palihawadana $\mathrm{TS}^{4}$
}

\begin{abstract}
Introduction: Hysterectomy is the commonest major gynaecological surgery performed worldwide. Though many routes of hysterectomy are described, open abdominal approach remains the commonest route to date for indications other than genital prolapse. There is evidence of advantages of non-descent vaginal hysterectomy (NDVH) over abdominal hysterectomy in such indications. However, the acceptance rate for vaginal approach by the gynaecologists remains low. We describe the outcome data of a series of non-descent vaginal hysterectomies performed in a single centre in Sri Lanka.
\end{abstract}

Objectives: To describe the post-operative outcome and complications of NDVH for benign indications of uteri less than 14 weeks size.

Method: An observational study was undertaken at the ward 14 of The De Soysa Maternity Hospital, Colombo over a period of one year from May 2007 to April 2008 among women who underwent NDVH for benign conditions. Those with co-existing genital prolapse requiring surgical correction, uteri larger than 14 weeks, a history of previous abdominal surgery and medical co-morbidities were excluded from the study.

Results: The study included 53 patients who underwent NDVH. The majority had a normal sized uterus $39(73.6 \%)$. There was a statistically significant improvement in post-operative urinary index compared to pre-operative urinary index [Kruskal-Wallis test-6.155, degrees of freedom $=2, p<0.05(0.046)]$. There was no difference in pre-operative and post-operative bowel function. The frequency of coitus and patient satisfaction appear to have improved post-surgery. Most patients $[n=45(85 \%)]$ had a faster than expected recovery. There were no visceral injuries and only one patient required blood transfusion following surgery. One patient developed a urinary tract infection. The mean post-operative hospital stay was 4.11 days (95\% $\mathrm{Cl}=3.48-4.74$ days).

Conclusions: The outcome and complication rates of non-descent vaginal hysterectomy this series were comparable with evidence from literature. Therefore, we conclude that NDVH is a feasible option for benign gynaecological conditions with a uterus less than 14 weeks in size in the current gynaecological practice of Sri Lanka.

\section{INTRODUCTION}

Hysterectomy is the commonest major gynaecological surgery worldwide and it is estimated over 600,000 such procedures are undertaken per year in $\mathrm{USA}^{1}$. There are several routes of hysterectomy, which include abdominal, vaginal, laparoscopic assisted vaginal and total laparoscopic

${ }^{1}$ De Soysa Maternity Hospital, Colombo, ${ }^{2}$ General Hospital, Mannar, ${ }^{3}$ University of Ruhuna, Matara, ${ }^{4}$ University of Kelaniya, Kelaniya.

Correspondence: Hiran Chaminda SH

E-mail: hiran.chaminda@yahoo.com

Competing interests: None hysterectomy. Abdominal approach with open laparotomy remains the commonest approach undertaken in Sri Lanka for benign conditions in the absence of genital prolapse.

Non-descent vaginal hysterectomy (NDVH) describes a vaginal approach that can be undertaken in the absence of uterine prolapse. It is performed entirely through the vagina routes and its advantages over abdominal and laparoscopic hysterectomy have been well documented. These include a lesser complications rate, lesser operative time and a faster convalescence ${ }^{2,3}$. Vaginal hysterectomy has also been found to be more cost-effective than laparoscopic hysterectomy ${ }^{4}$.
Despite these proven advantages there is hesitancy among gynaecologists to perform NDVH. The reasons could be many and include the misconceptions such as lack of uterine descent making it technically difficult, nulliparity limiting mobility of the uterus, inability to perform oophorectomy ${ }^{5}$.The American College of Obstetricians \& Gynaecologists (ACOG) and the Society of Pelvic Reconstructive Surgeons (SPRS) state that vaginal hysterectomy is more appropriate for a mobile uterus less than 12 weeks size $[280 \mathrm{~g}]^{6,7}$. However the choice should also be based on the clinical indication, patient choice, surgeon's training and experience ${ }^{6,7}$. The Society of Pelvic Reconstructive Surgeons (SPRS) guideline further states that a potential saving of US \$ 18000US $\$$ can be made for every 100 vaginal hysterectomies performed with a reduction of complications by $20 \%{ }^{7}$. However, the majority of hysterectomies are performed through laparotomy the world over. Hysterectomy trends from Australia from 2001 to 2011suggest that although abdominal hysterectomy rates have fallen from $49 \%$ to $34 \%$, vaginal hysterectomy rates have remained static at $35 \%$, and that laparoscopic hysterectomy rates have raised from $16 \%$ to $31 \%^{8}$.

Vaginal approach for hysterectomy is desirable in Sri Lankan since the health resources are limited. NDVH is performed in few centres within the country, according to preference of the clinicians, while many others do not offer it routinely. Uncertainly about its feasibility and complication rate could be responsible for reluctance by many to offer it. Outcome data of the procedure in a local setting would be helpful for both clinicians and the patients to consider a vaginal approach for hysterectomy. Therefore we undertook this study on the outcome and complications of NDVH in a single Sri Lankan centre. 


\section{METHODS}

An observational study was conducted at ward 14 of The De Soysa Maternity Hospital, Colombo over a period of one year from May 2007 to April 2008. All patients undergoing hysterectomy through the vaginal route was for indications other than genital prolapse were included in the study. Patients with uterine prolapse requiring surgical repair, a history of abdominal or pelvic surgery and medical co-morbidities (diabetes, ischaemic heart disease, immune suppressive disorders) were excluded from the study.

The unit followed a policy of preference of vaginal route over others in hysterectomy for benign conditions in presence of a uterus less than 14 weeks in size. All patients were consented for either NDVH or TAH and an examination was done under anaesthesia to assess the size and the mobility of the uterus. A NDVH was performed if deemed suitable and all procedures were carried out by a consultant gynaecologist. The decision to convert to laparotomy was at the discretion of the primary surgeon ${ }^{9}$.

Surgical technique: The patient was placed in lithotomy position with use of stirrups / leg holders after anaesthesia, taking care to avoid neurovascular compression. After cleaning and draping the cervix was held with vulsellum forceps. Saline infiltration was done to improve tissue dissection. A circumferential incision was made around the cervix and the bladder was pushed up and entry was made in to the vesico-uterine space. Afterwards the pouch of Douglas was entered into posteriorly. The cardinal, uterosacral ligaments and uterine vessels were clamped, cut and ligated. Uterine bisection, coring, morcellation were done if required. After removal of the uterus, a modified McCalls culdoplasty was done to suspend the vaginal vault. The vagina was be sutured with Vicryl 1 sutures.

All patients had a diclofenac sodium $100 \mathrm{mg}$ per rectally immediately after the surgery for pain relief. Further analgesics were according to the requirement. Operative details including any intra-operative complications were noted following the surgery. Post-operative complications were recorded from patient notes. All subjects were followed up at 10 days and three months post-operatively.

Data collection and data analysis: The basic demographic data were recorded for each patient such as age, parity as well as pre-operative findings such as general fitness (By American Society of Anaesthesiology grade or ASA grade) and uterine size. The main outcome variables included urinary, bowel, sexual function and these were assessed pre-operatively as well as at 10 days and 3 months following surgery. Urinary function was assessed using a questionnaire derived from the Urinary Distress Inventory short form (UDI-6) ${ }^{10}$. Patient satisfaction, post-operative hospital stay and intra-operative or postoperative complications were also assessed.

The study did not raise major ethical issues since it was a non-interventional observational study done to assess outcome of a surgical procedure that is in clinical practice. The study was approved by the board of study in Obstetrics and Gynaecology of the Post Graduate Institute of Medicine prior to its commencement.

\section{RESULTS}

The study included a total of 53 patients who underwent NDVH during the study period. The basic characteristics of the subjects are shown in Table 1.The indications for hysterectomy are shown in Table 2 .

Majority of subjects had a normal sized uterus $(n=39,73.6 \%)$, while it was normal to 10 weeks size in seven $(13.2 \%), 10-12$ weeks size in six $(11.3 \%)$ and $12-14$ weeks size one $(1.9 \%)$ patient.

There was a statistically significant improvement in post-operative urinary index compared to preoperative urinary index score [Kruskal- Wallis test-6.155, degrees of freedom $=2, \mathrm{p}<0.05(0.046)]$ (Table 3). There was no difference between preoperative and post-operative bowel function (Table 4) while the frequency of coitus (Table 5) and patient satisfaction appear to have increased post-surgery (Table 6).

There were no patients with visceral injury and only one patient required a blood transfusion. There was only one patient with a urinary tract infection (Table 7). The mean post-operative hospital stay was 4.11 days (95\% $\mathrm{CI}=3.48-4.74$ days).

In assessment of patient perception of recovery, a majority $[\mathrm{n}=45(85 \%)]$ had a faster than expected recovery. Seven patients $(13.2 \%)$ said recovery was as they had expected while only one patient $(1.9 \%)$ said recovery was slower than expected.

Table 1.The description of the basic characteristics of the study population.

\begin{tabular}{|l|l|}
\hline Basic characteristics & \\
\hline Age; mean $(95 \% \mathrm{Cl})$ & $44.94 \mathrm{yrs}(39.85-50.03)$ \\
\hline Parity; median & 3 \\
\hline General fitness according to ASA $^{*}$ Grade; no (\%) & \\
\hline 1 & $49(92.4 \%)$ \\
\hline 2 & $3(5.6 \%)$ \\
\hline Not known & $1(2 \%)$ \\
\hline
\end{tabular}

${ }^{\star}$ American Society of Anaesthesiologists 
Table 2. Primary indication for hysterectomy.

\begin{tabular}{|l|l|}
\hline Indication & $\mathbf{n}(\%)$ \\
\hline Dysfunctional uterine bleeding & $35(66 \%)$ \\
\hline Fibroid uterus & $8(16 \%)$ \\
\hline Chronic pelvic pain & $2(3 \%)$ \\
\hline Adenomyosis & $6(12 \%)$ \\
\hline Others(simple endometrial hyperplasia, endometrial polyp) & $2(3 \%)$ \\
\hline Total & \\
\hline
\end{tabular}

Table 03. The distribution of the study population according to presence of bladder dysfunction before and after surgery.

\begin{tabular}{|l|l|l|l|}
\hline Bladder dysfunction & Pre-operative & 10 days post-operative & 3 months post-operative \\
\hline None; no (\%) & $40(75.5 \%)$ & $46(86.8)$ & $49(92.4)$ \\
\hline Mild; no (\%) & $12(22.6 \%)$ & $6(11.3)$ & $4(7.6)$ \\
\hline Moderate; no (\%) & $1(1.8 \%)$ & $1(1.9)$ & 0 \\
\hline Severe; no (\%) & 0 & 0 & 0 \\
\hline Total & 53 & 53 & 53 \\
\hline
\end{tabular}

Kruskal- Wallis test-6.155, degrees of freedom $=2, p=0.046$

Table 04. The distribution of the study population according to presence of bowel symptoms before and after surgery.

\begin{tabular}{|l|l|l|l|}
\hline Bowel symptom & Pre-operative & 10 days post-operative & 3 months post-operative \\
\hline Constipated; no (\%) & $5(9.4)$ & $1(1.9)$ & 0 \\
\hline None; no (\%) & $48(90.6)$ & $52(98.1)$ & $53(100)$ \\
\hline Loose stool; no (\%) & 0 & 0 & 0 \\
\hline Total & 53 & 53 & \\
\hline
\end{tabular}

*Fisher's exact test used. Pre-operative $v$ s. post-operative ten days. $\mathrm{P}=0.102$

Table 05. The distribution of the study sample according to frequency or sexual intercourse before surgery and three months following surgery

\begin{tabular}{|l|l|l|}
\hline $\begin{array}{l}\text { Frequency of intercourse per } \\
\text { month }\end{array}$ & Pre-operative & 3 months post-operative \\
\hline 1 or less; no (\%) & $40(75.4)$ & $11(20.8)$ \\
\hline $2-5 ;$ no (\%) & $5(9.4)$ & $35(66.1)$ \\
\hline $6-10 ;$ no (\%) & $1(1.9)$ & $2(3.8)$ \\
\hline $11-15 ;$ no (\%) & 0 & 0 \\
\hline No reply; no (\%) & $7(13.3)$ & $7(13.3)$ \\
\hline Total & $53(100)$ & $53(100)$ \\
\hline
\end{tabular}

Table 06: The distribution of the study population according to satisfaction of sexual function

\begin{tabular}{|l|l|l|}
\hline Patient satisfaction & Pre-operative & 3 months post-operative \\
\hline Poor; no (\%) & $10(18.9)$ & $2(3.8)$ \\
\hline Fair; no (\%) & $21(39.6)$ & $35(66)$ \\
\hline Good; no (\%) & $11(20.1)$ & $12(22.6)$ \\
\hline Very good; no (\%) & $5(9.4)$ & $1(1.9)$ \\
\hline No reply; no (\%) & $6(11.3)$ & $3(5.7)$ \\
\hline Total & 53 & 53 \\
\hline
\end{tabular}


Table 07. The rate of intra-operative or post-operative complications following NDVH among the study population.

\begin{tabular}{|l|l|}
\hline Complication & $\mathrm{n}(\%)$ \\
\hline Intra-operative complications & \\
\hline Bladder/ureteric/bowel injury & 0 \\
\hline Haemorrhage needing blood transfusion & $1(1.8 \%)$ \\
\hline Conversion to laparotomy & 0 \\
\hline Anaesthetic complications & 0 \\
\hline Post-operative complications & \\
\hline Urinary tract infection & $1(1.8 \%)$ \\
\hline Wound infection & 0 \\
\hline Vault haematoma & 0 \\
\hline DVT/PE & 0 \\
\hline Unspecified fever (>380C) & 0 \\
\hline
\end{tabular}

\section{DISCUSSION}

This study, albeit observational, shows that non-descent vaginal hysterectomy is feasible and safe in our clinical setting since 53 cases were done in a single unit in one year with minimal complications. Our finding of an improvement in post-hysterectomy urinary function is in contrast to findings of previous studies that have shown deterioration in urinary function showing a higher prevalence of urgency and urge incontinence following surgery ${ }^{11},{ }^{12}$. Urinary function was assessed in this study using a questionnaire based on the UDI-6 through a face-to-face interview with the patient since there are no validated questionnaires available in Sinhala language. We feel although not ideal, it was an objective assessment of the bladder functions. Although retrospective studies suggest a deterioration in bowel function ${ }^{13,14}$, prospective studies have shown an improvement in symptoms following hysterectomy ${ }^{15}$. Our study is in line with Prior et al as there was no significant change in bowel habits after hysterectomy ${ }^{15}$.

The eVALuate trial compared vaginal hysterectomy with laparoscopic hysterectomy in one arm and abdominal hysterectomy with laparoscopic hysterectomy in the other arm concluded that laparoscopic hysterectomy is not cost-effective compared to vaginal hysterectomy ${ }^{16}$. To date this is the largest randomized multicentre trial on hysterectomy and this suggests that vaginal hysterectomy is the ideal route of hysterectomy. The total major complication rate was $9.5 \%$ for vaginal hysterectomy in the eVALuate trial ${ }^{17}$. Although our major complication rate of $3.6 \%$ was significantly lower than that reported in the eVALuate trial there were only 53 patients whilst there were 186 patients who underwent vaginal hysterectomy in the eVALuate trial. The length of hospital stay after surgery in our study was similar to that reported by Sculpher et al for the eVALuate trial However other studies have reported shorter hospital stays following vaginal hysterectomy ${ }^{18}$. This can be explained by the fact that the post-operative hospital stay can be influenced by patient expectations and individual practice of gynaecologists ${ }^{19}$. Therefore it is important to define discharge criteria if post-operative hospital stay is to be assessed in an objective manner.

Though it provides us some valuable information on the feasibility of performing NDVH in local settings, the study had some limitations. Firstly, a comparative study between NDVH and $\mathrm{TAH}$, the common alternative, would have been more informative on the superiority of one over the other. The other drawback is the subjective nature of the pre-operative evaluation such as assessment of the uterine size, which was based on clinician assessment alone that is known to be subjective. An objective assessment in terms of uterine weight would have been a more scientific method as done by Benassi et $a l^{20}$. The suitability for the procedure was according to the clinical judgement of the operating clinician, which again is subjective thus limiting the external validity of the recommendations.

Two important aspects that were not studied in this study were the operating time, which is an important aspect in the resource poor setting as well as the pain scores of patient post operatively. These aspects should be studied in any future study by recording the start and end times of the surgery and by measuring the pain using a visual analogue scale (VAS) ${ }^{21}$. The follow up period was limited in our study due to resource constraints to three months whereas in many other studies it has been done up to one year post operatively ${ }^{22,18}$.

\section{CONCLUSIONS}

We conclude according to the findings of this study that NDVH is a feasible option in Sri Lankan setting with good outcome and low complications rates that are comparable with data reported in other studies. Clinicians should consider offering this approach to more patients in routine clinical practice due to its known advantages. More studies comparing this approach with other alternatives such as abdominal route and laparoscopic approaches should be done and outcome, complications as well as cost effectiveness of NDVH in comparison to other methods should be done in the local setting. 


\section{REFERENCES}

1. Carlson KJ, Nichols DH, Schiff I. Indications for hysterectomy. N Engl J Med 1993; 328:856-60.

2. Nieboer TE, Johnson N, Lethaby A, et al. Surgical approach to hysterectomy for benign gynaecological disease. Cochrane Database of Systematic Reviews 2009, Issue 3. Art. No.: CD003677. DOI: 10.1002/14651858.CD003677.pub4.

3. Maresh MJ, Metcalfe MA, McPherson K, et al. The VALUE national hysterectomy study: description of the patients and their surgery. BJOG 2002; 109:302-312.

4. Schulpner M, Manca A, Abbott J, et al. Cost effectiveness analysis of laparoscopic hysterectomy compared with standard hysterectomy: results from a randomized trial. BMJ 2004; 328: 134.

5. Oláh, K. S. Vaginal hysterectomy in the absence of prolapse. The Obstetrician and Gynaecologist 2005; 7: 233-240.

6. Kovac SR et al. Guidelines for the selection of the route of hysterectomy: Application in a resident clinic population. Am J Obstet Gynecol 2002; 187(6):1521 $-1527$.

7. Kovac SR. Decision-directed hysterectomy: a possible approach to improve medical and economic outcomes. Int J GynecolObstet 2000; 71:159-69.

8. http://www.ranzcog.edu.au/editions/ doc_view/1015-38-hysterectomy.html (accessed on $25^{\text {th }}$ April 2007)
9. Lopes T, Spirtos N, Naik R, Monaghan J. Bonney's Gynaecological Surgery. $11^{\text {th }}$ ed. New Delhi: Wiley-Blackwell; 2010. Chapter 11, Operations on the uterus; $p$ 112.

10. Barber MD,Walters MD,Bump RC,Short forms of two conditions-specific quality of life questionnaires for women with pelvic floor disorders(PFDI-20 and PFIQ-7).Am J Obstet Gynecol.2005:193,103-13

11. Vervest $H A$, Kiewiet de Jonge M, Vervest TM, Barents JW, Haspels AA. Micturition symptoms and urinary incontinence after non-radical hysterectomy.Acta Obstet Gynecol Scand 1988; 67(2):141-6.

12. Roovers JP, van der Bom JG, Huub van der Vaart C, Fousert DM, Heintz AP. Does mode of hysterectomy influence micturition and defecation? Acta Obstet Gynecol Scand 2001;80(10):945-51.

13. Taylor T, Smith AN. Effect of hysterectomy on bowel function. BMJ 1989; 299:300302.

14. Van Dam JH, Gosselink MJ, Drogendijk AC, Hop WC, Schouten WR. Changes in bowel function after hysterectomy. Dis Colon Rectum 1997; 40:1342-1347.

15. Prior A, Stanley K, Smith ARB, Read NW. Relation between hysterectomy and irritable bowel syndrome: a prospective study. Gut 1992; 33:814-817.

16. Garry R, Fountain J, Brown J, Manca A, et al.EVALUATE hysterectomy trial: a multicentre randomised trial comparing abdominal, vaginal and laparoscopic methods of hysterectomy. Health Technol
Assess 2004;8(26):1-154.

17. Garry R, Fountain J, Mason S, Hawe J, et al. The eVALuate study: two parallel randomized trials, one comparing laparoscopic with abdominal hysterectomy, and the other comparing laparoscopic with vaginal hysterectomy. BMJ. 2004; 328(7432):129.

18. Abdelmonem $\mathrm{A}$, Wilson $\mathrm{H}$, Pasic R.Observational comparison of abdominal, vaginal and laparoscopic hysterectomy as performed at a university teaching hospital.J Reprod Med. 2006; 51(12):945-54.

19. Lumsden MA, Twaddle S, Hawthorn R, Traynor I, Gilmore D, Davis J, Deeny M, Cameron IT, Walker JJ. A randomized comparison and economic evaluation of laparoscopic-assisted hysterectomy and abdominal hysterectomy.BJOG. 2000 Nov; 107(11):1386-91.

20. Benassi L, Rossi T, Kaihura CT, Ricci L, Bedocchi L, Galanti B, Vadora E. Abdominal or vaginal hysterectomy for enlarged uteri: a randomized clinical trial. Am J Obstet Gynecol 2002; 187(6):15615.

21. Svensson I, Sjöström B, Haljamäe H.Assessment of pain experiences after elective surgery.J Pain Symptom Manage 2000; 20(3):193-201.

22. Kluivers $\mathrm{KB}$, Mol BW, Bremer GL, Brölmann HA, Vierhout ME, Bongers MY. Pelvic organ function in randomized patients undergoing laparoscopic or abdominal hysterectomy. J Minim Invasive Gynecol 2007; 14(4):442-8. 